PRESTES, Ana Maria; PAUTASSO, Diego (Org.).

Teoria das relações

internacionais:

contribuições marxistas

Editoras: Anita Garibaldi /

Contraponto

Formato: $16 \times 23 \mathrm{~cm}$

$1^{a}$ edição: 2021

Preço: R\$ 55

324 páginas

\title{
Relações internacionais: o marxismo e o caráter global do capitalismo
}

International relations: Marxism and the global character of capitalism 
Prestes, além de carregar o legado do sobrenome do Cavaleiro da Esperança, tem longa trajetória de atuação na área de relações internacionais, desde o período em que cursou Ciências Sociais na Universidade Federal de Minas Gerais (UFMG). Ao longo desse período, ocupou funções de destaque, especialmente no Conselho Internacional do Fórum Social Mundial. Fez mestrado e doutorado em Ciência Política, também pela UFMG, e atua como professora voluntária do Decanato de Extensão da Universidade de Brasília (UnB).

Pautasso é geógrafo, graduado pela Universidade Federal do Rio Grande do Sul (UFRGS), onde cursou também seu mestrado e doutorado. Atualmente é professor de Geografia do Colégio Militar de Porto Alegre e colaborador do curso de Especialização em Estratégia e Relações Internacionais Contemporâneas na UFRGS.

No livro, o leitor encontrará um conjunto de artigos escritos por dirigentes políticos, ativistas e pesquisadores especialistas no referido campo de estudos. Entre os temas abordados, destacam-se as contribuições de inúmeros pensadores marxistas e dirigentes políticos históricos dos movimentos revolucionários em nível internacional. É o caso do capítulo escrito por Rita Coitinho, que se dedica a desenvolver as contribuições de Lênin para o entendimento das relações internacionais contemporâneas. Coitinho (202I, p. 47) destaca as elaborações do revolucionário russo e as relações entre a teoria do imperialismo e o novo sistema global do capitalismo, característico do início do século XX. Esse debate é retomado no texto desenvolvido por Ana Maria Prestes (PRESTES; PAUTASSO, 202I, p. I25), no qual a coorganizadora da obra busca estabelecer paralelos entre as noções de hegemonia de Lênin e de Gramsci. Seu esforço nesse sentido tem por objetivo evidenciar os subsídios do sociólogo italiano Giovanni Arrighi no desenvolvimento do conceito de hegemonia mundial a partir de Gramsci. Evidenciam-se, assim, os debates teóricos no campo do marxismo com base nos aportes de ambos os dirigentes, assim como nas interpretações gramscianas sobre as disputas globais. Ou, ainda mais, buscam-se as reflexões do próprio Marx acerca do caráter global do capitalismo e seu diálogo com as teorias de relações internacionais, como o leitor encontrará nos trabalhos de Luis Fernandes (PRESTES; PAUTASSO, 202I, p. 9), professor da Pontifícia Universidade Católica do Rio de Janeiro (PUC-Rio), e do italiano Gianni Fresu (PRESTES; PAUTASSO, 202I, p. 2I), professor da Universidade Federal de Uberlândia.

Além disso, outros trabalhos desenvolvidos na publicação agora analisada resgatam debates importantes no terreno das interpretações acerca do caráter dependente do capitalismo formado nos países coloniais e nas relações centroperiferia. O debate sobre a teoria da dependência segue com a participação de Tiago Nogara, mestre em Relações Internacionais pela UnB e doutorando em Ciência Política pela Universidade de São Paulo (USP). Nogara (PRESTES; PAUTASSO, 202I, p. 2II) oferece importantes aportes para as discussões acerca da perspectiva em torno da existência, ou não, de um "subimperialismo brasileiro", categoria desenvolvida pelo intelectual e militante brasileiro Ruy Mauro Marini (MARINI, 


\section{Uma das grandes contribuições do livro,} organizado por Ana Prestes e Diego Pautasso, consiste em compreender que as relações internacionais estabelecidas no âmbito de um sistema social de caráter global são pautadas pela força. Essas conexões são permeadas por contradições provocadas pelo estágio de desenvolvimento de cada país, o que determina a capacidade de cada nação em interferir nos rumos do planeta

I990, p. I8). A perspectiva latino-americanista também se faz presente na obra pela exposição de Américo Lyra, professor da Universidade Federal de Roraima (UFRR), sobre o marxismo de José Carlos Mariátegui e a questão indígena. Ainda no terreno dos pensamentos decoloniais (QUIJANO, 2000), é fundamental mencionar a interpretação de Diego Pautasso (PRESTES; PAUTASSO, 202I, p. 79) sobre o papel de Domenico Losurdo e suas abordagens acerca do neocolonialismo e do universalismo imperialista. O capítulo contribui centralmente para a compreensão acerca dos impactos que as perspectivas hegemônicas provocam nas organizações de esquerda a partir das interpretações do filósofo italiano. Losurdo afirmou que a esquerda ocidental reproduz a visão hegemônica em vez de combatê-la. Ou seja, um belo debate espera pelos leitores.

É possível identificar o esforço dos colaboradores do livro Teoria das relações internacionais: contribuições marxistas ao analisarem a referida área do conhecimento pela perspectiva da luta de classes. É o que pode ser encontrado no capítulo construído por Mariana Davi Ferreira, doutoranda em Ciência Política pela Universidade Estadual de Campinas (Unicamp), e Tatiana Berringer, professora adjunta do curso de Relações Internacionais da Universidade Federal do ABC (UFABC). Ali, as autoras destacam o pensamento de Nicos Poulantzas e a concepção de uma teoria marxista do Estado compreendida como pilar estratégico para a compreensão das relações internacionais. A partir desse entendimento é possível indicar a manifestação de conflitos que marcam a sociedade na esfera das relações interestatais. Sendo assim, as pesquisadoras apontam para a possibilidade de formação 
de blocos contra-hegemônicos, especialmente no contexto regional latino-americano. Essa mesma toada segue o texto de Jaime Cesar Coelho, professor de Economia e Relações Internacionais da Universidade Federal de Santa Catarina (UFSC), e Miguel Borba de Sá, professor auxiliar convidado de Relações Internacionais da Faculdade de Economia da Universidade de Coimbra, Portugal, e doutor em Relações Internacionais pela PUC-Rio. A colaboração desses acadêmicos consiste em trazer à tona as reflexões do intelectual canadense Robert Cox a respeito das dinâmicas que caracterizam as mudanças em nível global.

Por fim, e não menos importante, podemos situar as leituras acerca do entendimento da ordem global como reflexo das matrizes sociais e econômicas do cenário do mundo globalizado. É o que salientam Leonardo Ramos e Rodrigo Corrêa, ambos professores da Pontifícia Universidade Católica de Minas Gerais (PUC Minas), conjuntamente com Marina Scotelaro, professora do curso de Relações Internacionais do Centro Universitário de Belo Horizonte (UNI-BH). A contribuição do trio traz a compreensão do britânico David Harvey quanto aos estudos contemporâneos dos processos de acumulação capitalista marcados pela integração desigual das matrizes produtivas em âmbito planetário. A obra é coroada com uma belíssima análise acerca da China, que tem um papel estratégico no que diz respeito ao equilíbrio de poder internacional. Para os autores do capítulo, a "nova economia do projetamento" parte da análise materialista e dialética da realidade, que permite entender o mercado enquanto fenômeno histórico-social. Livrando-se da perspectiva liberal, é possível identificar na China a construção de uma formação social intermediária, na qual o mercado está a serviço da sociedade, e não o contrário. Assim, Elias Jabbour e Alex Dantas, professores da Universidade do Estado do Rio de Janeiro (Uerj), Carlos Espíndola, da UFSC, e Julio Velozo, da Universidade Presbiteriana Mackenzie, discorrem sobre a alternativa chinesa e o papel dessa potência asiática no contexto global.

\section{RELACÕ̃ES INTERNACIONAIS}

Ao longo da trajetória das civilizações que marcaram a história da humanidade, a prática de algo que pode chamar-se diplomacia sempre teve presença na resolução de conflitos, acordos econômicos ou tratados políticos. A singularidade das relações internacionais estabelecidas na contemporaneidade consiste no fato de que estas se desenvolvem nos marcos da sociedade capitalista e no contexto dos modernos Estados nacionais. Aí reside a primeira contribuição de Marx às teorias de relações internacionais que o livro levanta: compreender o caráter global e globalizante do capitalismo. "O capitalismo europeu, assim, já nasce imbricado em fluxos globais de comércio e riqueza. Ele se forma e desenvolve, portanto, como sistema transnacional desde o seu início." (PRESTES; PAUTASSO, 202I. p. I3). Assim, partindo da compreensão de Marx, pode-se afirmar que o mundo capitalista moderno já nasce sob uma perspectiva de projeção internacional. 
Entretanto, a compreensão totalizante presente no pensamento marxista tem sido, historicamente, marginalizada no âmbito das teorias de relações internacionais, assim como na academia de maneira geral. Para Luis Fernandes, um dos integrantes do belíssimo elenco que compõe a obra analisada, esse fenômeno se sustenta no fato de que os temas vinculados às relações internacionais estiveram, majoritariamente, circunscritos ao âmbito do direito internacional. Este, por sua vez, remonta ao processo de consolidação dos Estados nacionais no início da Modernidade, acompanhado do fortalecimento do liberalismo, especialmente de suas visões contratualistas. Desse modo, as relações internacionais acabaram sendo encaradas apenas como relações interestatais desenvolvidas entre nações soberanas, e não integrantes de um modo de produção de caráter global.

Assim, é possível identificar que o capitalismo desenvolve-se integrado a uma espécie de sistema-mundo desde antes mesmo da sua existência enquanto sistema social. Ainda durante a transição da Idade Média para a Modernidade, o surgimento de feiras e rotas comerciais impulsionadas pela burguesia exigiam o estabelecimento de um conjunto de pactos comerciais e jurídicos entre os distintos reinos europeus. Diante do poder fragmentado que caracterizou o medievo, os acordos comerciais assumiram feições distintas de acordo com a moeda, padrões de peso e medida, leis e impostos de cada reino ou feudo. Com o impulso das Cruzadas, especialmente na sua quarta edição, esses acordos assumiram dimensões regionais, envolvendo as nobrezas européias, que buscavam ampliar seu poder político, o Vaticano, que desejava expandir a fé cristã e combater os "infiéis", e a burguesia, ávida por novos mercados. Processo homólogo a esse pode ser encontrado, igualmente, na península Ibérica, onde a união desses atores resultou na guerra contra o reino de Al-Andaluz e a presença árabe na região. Dessa Cruzada direcionada à Europa Ocidental, conhecida como Reconquista, originaram-se os dois primeiros Estados-nação da Era Moderna. Portugal e Espanha surgem, então, como expressão de uma nova experiência, e a formação de grandes territórios cristãos, controlados por um rei com condições favoráveis para o desenvolvimento de um mercado potente no contexto europeu. Esse "grande pacto" permitiu a formação de um bloco histórico que abriu caminho para o processo de padronização das moedas, adoção de idiomas nacionais, criação de leis comuns, critérios similares para pesos e medidas etc. Esse percurso permitiu que o condado de Portucale, um pequeno território que vivia da pesca, se tornasse uma das maiores potências mundiais do começo da Era Moderna. Assim, o processo de transição que levou ao surgimento do capitalismo já anunciava a tendência expansionista do modo de produção que se consolidou posteriormente, conforme observou Marx, ao mesmo tempo associado à formação dos Estados Nacionais, como Luis Fernandes (PRESTES; PAUTASSO, 202I, p. I8) salienta no livro:

Marx indica que o surgimento de um sistema de Estados soberanos no noroeste da Europa do século XVII foi fruto de um processo histórico muito particular e concreto, associado ao advento de novas formas produtivas via o impulso comercial propiciado 
pelos descobrimentos. As novas relações sociais gestadas por esse processo constituíram o elo institucional central que articula o mundo moderno: a existência separada de esferas políticas e econômicas autônomas, tanto em nível doméstico quanto internacional. É essa separação que permite e viabiliza, via uma estrutura legal de direitos de propriedade, fluxos de investimento para além das fronteiras nacionais.

Não à toa, o ano de I492 não marca apenas a reconquista da península Ibérica pelos cristãos, mas também a chegada de Colombo à América.

Entretanto, nessa fase do desenvolvimento capitalista, a burguesia é uma nova força que desponta no cenário europeu diante de dois atores tradicionais e mais fortes: clero e nobreza. Por isso, os colaboradores de Teorias das relações internacionais: contribuições marxistas, localizam no século XIX a formação dos pilares do sistemamundo atual. Ana Maria Prestes identifica que,

\begin{abstract}
segundo Arrighi, "o Reino Unido exerceu as funções de governo mundial até o fim do século XIX", e a ascensão da Alemanha foi o primeiro elemento desestabilizador de sua supremacia. Paralelamente à ascensão germânica, o desenvolvimento dos Estados Unidos e sua capacidade de atração de mão de obra, capital e espírito de iniciativa começaram a minar o Império Britânico. Alemanha e Estados Unidos serão, portanto, os protagonistas de uma luta entre tendências hegemônicas instalada no caos sistêmico que precede a ascensão de uma nova hegemonia (PRESTES; PAUTASSO, 202I, p. I47).
\end{abstract}

As revoluções de caráter liberal e a industrialização das economias da Europa representaramum saltodequalidadeimportanteparaa constituição dasrelações sociais de tipo capitalista hegemônicas no Velho Continente e daí para todo o planeta. Assim, com a formação dos novos Estados-nação, constituídos a partir das diversas estruturas de poder burguês em torno de mercados nacionais, o direito internacional ganhou força. Diante do cenário de expansionismo europeu na busca da abertura de novos mercados consumidores ou fornecedores de matérias-primas, viu-se a necessidade de estabilizar a concorrência entre os países, Alemanha e Inglaterra principalmente. Nesse cenário, marcado pela luta de hegemonias em torno da liderança do mundo capitalista, é possível identificar a formação de pactos e alianças entre países com interesses afins. De um lado, a Santa Aliança, envolvendo as velhas aristocracias do Antigo Regime vitoriosas sobre Napoleão, que envolviam o Império Austro-Húngaro, o Império Russo e a Prússia; de outro, a Entente Cordiale, que aproximou Inglaterra e França, inimigos históricos. Prevendo o conflito que se originaria em virtude das disputas entre as potências europeias por territórios, mercados e matérias-primas de todo o planeta, o chanceler alemão Otto von Bismarck organizou a Conferência de Berlim em I885, que estabeleceu parâmetros para garantir o equilíbrio nas posses europeias sob territórios no continente africano. Essa iniciativa, porém, apenas adiou o primeiro grande conflito de caráter global: a Primeira Guerra Mundial. Após a guerra "para acabar com todas as guerras", a criação da Liga das Nações representou 
a primeira tentativa de criação de um órgão de governança global. Contudo, como sabemos, essa experiência não foi exitosa, considerando a ocorrência da Segunda Guerra Mundial logo em seguida. Desse processo, no entanto, surge a ONU, como instrumento global de governança, sobretudo para fazer frente ao bloco soviético, que se fortalecia no pós-guerra.

\section{CONTRIBUICÕ̃ES MARXISTAS}

Outro aspecto importante a se destacar na obra Teoria das relações internacionais: contribuições marxistas consiste no fato de que, ao abordar os debates no âmbito das relações internacionais, os autores promovem reflexões importantíssimas acerca do marxismo. Em primeiro lugar, situando a perspectiva marxista em relação às relações internacionais, que teve como norte o entendimento do capitalismo como sistema global, conforme já mencionamos anteriormente. Mas gostaria de destacar, primeiramente, um elemento que martelou na minha cabeça ao longo da leitura da obra: a virada de I8o graus que Marx e Engels promovem através dos seus estudos referentes à questão nacional na Irlanda e Rússia, principalmente. Conforme Pautasso (PRESTES; PAUTASSO, 202I, p. 89),

\footnotetext{
leituras apressadas e anacrônicas costumam atribuir ao próprio Marx um viés etnocêntrico. Primeiro, se desconsidera o contexto do século XIX e a evolução da obra do autor, pois o Marx maduro abordou com preocupação o colonialismo, a opressão e as lutas de libertação nacional. Suas análises sobre Índia, Argélia, Indonésia e China foram se tornando mais complexas, pois à dinâmica do capital somavam-se elementos (etnia e nacionalidade) para compor totalidade [...]. Segundo, tais análises são contrafatuais, dado que os partidos comunistas compuseram um campo que, no seu ápice nos anos 1980, alcançou 32 nações e um terço da população mundial, transformando um país atrasado numa superpotência, promovendo processos de modernização e abrindo caminho para experiências inéditas de governo - e algumas, como na China, Cuba e Coreia Popular, seguem resistindo e se reinventando na atualidade.
}

Esses estudos marcam uma virada no pensamento dos autores na medida em que deslocam o centro de referência de suas análises. Se antes Marx e Engels acreditavam que a revolução deveria ocorrer primeiramente nos países centrais do capitalismo, identificando a libertação dos trabalhadores ingleses como condição sine qua non para a libertação dos operários irlandeses, a partir de I870 essa agenda se inverteu (ARICÓ, 1982, p. 54-55). Ou seja, os autores do Manifesto comunista já desenvolviam a visão de que, para conquistar a emancipação social, seria preciso romper com o sistema hegemônico internacional imposto pelas potências capitalistas.

A polêmica "libertação nacional versus social" ocupou os debates no campo do marxismo por muitos anos durante o século XX. As visões esquemáticas acerca da Revolução Russa, predominantes em meados do século passado, levaram à formulação de uma visão conhecida como etapismo. A partir dessa perspectiva, dividia-se a história 
da humanidade em etapas estanques pelas quais todas as sociedades deveriam passar para tornar possível a construção do socialismo. Sendo assim, a formação distorcida e incompleta do capitalismo originado nos países que foram colonizados exigia o cumprimento da etapa capitalista, ou nacional-burguesa, para se avançar em direção ao socialismo. Sob essa perspectiva, o desenvolvimento desigual entre as sociedades capitalistas e as contradições entre burguesias de distintos países fizeram com que muitos marxistas apontassem para um suposto caráter nacionalista, anti-imperialista e até revolucionário das "burguesias nacionais" desses países. Conforme afirma Anita Prestes, entendia-se que havia dois campos:

"um genuinamente nacional e outro que tem seus negócios ligados num grau maior ou menor ao capital imperialista". Sendo que "o primeiro constitui a imensa maioria da burguesia brasileira". Dizia-se ainda: "a burguesia tomada no seu conjunto apresenta duplo caráter. Pertencendo a um país economicamente explorado pelo imperialismo, é uma força revolucionária. Mas seu revolucionarismo é limitado, como o de toda classe exploradora. Da mesma maneira que na Declaração de março, concluía-se que a suposta burguesia nacional deveria ser incluída entre as forças que participariam da etapa nacional e democrática da revolução brasileira, segundo a visão do PCB (PRESTES, 2015, p. 333).

Por isso, eventos como a Revolução Cubana bagunçaram a cabeça de muita gente, uma vez que não se encaixava nos formulismos pré-estabelecidos. Aliás, convenhamos que, se uma revolução não representar a quebra dos paradigmas vigentes, deve ser nomeada de outra forma. Nesse contexto, os marxistas ligados à teoria da dependência ou ao pensamento cepalino buscaram analisar a busca pela implementação de projetos verdadeiramente autônomos, identificando que estes seriam possíveis apenas através de uma ruptura com os pilares que estruturam a nossa dependência e subdesenvolvimento. Ou seja, a revolução social, e consequentemente o socialismo, seria o instrumento pelo qual os povos poderiam libertar-se do domínio imperialista e do passado colonial. Por outro lado, é importante destacar que a libertação nacional não se limita ao simples estatuto jurídico da soberania nacional, mas integra a própria disputa pela implementação de um modelo de desenvolvimento. Para Diego Pautasso, a partir da interpretação de Losurdo acerca da discussão, "não seria exagerado ensaiar que a questão nacional é o enlace entre soberania e desenvolvimento e, por sua vez, a amálgama possível para as diversas lutas emancipatórias" (PRESTES; PAUTASSO, 202I. p. 9I). Um sistema que, consequentemente, promova a libertação da classe e da nação e, em última instância, segundo Marx e Engels, da própria humanidade. Ou seja, para os revolucionários comunistas há uma relação dialética entre os aspectos internos e externos tanto do processo de constituição do capitalismo quanto dos movimentos de emancipação. Essa concepção pode ser identificada, também, na consigna histórica do movimento comunista que conclama os operários de todos os países a uniremse. Partindo dessa mesma concepção, Mariátegui já identificava a impossibilidade 
das "burguesias nacionais" dos países subdesenvolvidos de conduzir processos de verdadeira emancipação nacional. Para o peruano, a formação desses grupos estava marcada pelo aburguesamento das elites coloniais, que constituíram novas estruturas de dominação a partir da emancipação política das colônias. Por estarem presas ao latifúndio colonial sempre representaram um entrave ao desenvolvimento dos países latino-americanos. Libertar o Peru, no caso, seria possível, apenas, através da constituição de um poder popular e revolucionário que promovesse a ruptura com esse passado colonial.

Nesse contexto, outro elemento que podemos apreender da obra é a contribuição de Lênin para essa formulação. Diferentemente de Marx, Lênin produziu sua elaboração intelectual à luz do debate sobre a condução do processo de tomada do poder de maneira revolucionária e a construção de uma nova ordem social. "Ele percebeu que não era somente com o uso da violência e da repressão do Estado que uma determinada classe buscava a condição de dominação, mas também através da formação de alianças em torno de interesses sociais e experiências políticas." (PRESTES; PAUTASSO, 202I, p. I26). Ou seja, para o líder russo, a questão da hegemonia tinha perspectiva de direção política, com o objetivo de materializar a formação de um novo bloco social e histórico que conduzisse as transformações estruturais que o momento exigia. A natureza política da liderança do proletariado relaciona-se com um contexto econômico e social em que o proletariado não constitui a maioria numérica dos trabalhadores. Sendo assim, Lênin refere-se a alianças sociais sob direção política do proletariado. Essa direção, no entanto, é construída politicamente pela autoridade, pelo exemplo, protagonismo, capacidade de liderança e constituição de sensos comuns no bloco social constituído, ou seja, em um ambiente de lutas por hegemonias. Para Ana Maria Prestes (PRESTES; PAUTASSO, 202I, p. I27), Lênin entendia que,

se o proletariado, por exemplo, quisesse construir uma hegemonia política sobre o restante da sociedade, precisaria abandonar "o estreito limite da luta econômica contra o patrão e o governo" e se colocar na linha de frente das lutas "contra qualquer manifestação de arbitrariedade e de opressão, onde quer que ela se produza, qualquer que seja a classe ou camada social atingida”.

O imediatismo das necessidades impostas a Lênin impedia diletantismos de qualquer ordem, uma vez que ele tinha diante de si a necessidade de reunir forças para enfrentar apoiadores do czar e os exércitos de I4 potências internacionais, além de alimentar a população.

Partindo desse entendimento a respeito do marxismo leninista, devemos superar as visões que limitam o conceito de hegemonia ao âmbito cultural, essas são visões fragmentárias do processo. Gramsci tem uma visão de totalidade materialmente dialética que supera apenas os aspectos políticos ou culturais que são destacados por muitos autores. De toda forma, compreende-se tal ênfase, diante das contribuições de Gramsci para a superação de um marxismo economicista ou demasiadamente esquemático. Ele nos ajuda a compreender as relações internacionais à luz de uma 
perspectiva estruturante que permite identificar o atual sistema-mundo como a constituição de blocos sociais heterogêneos e dialeticamente contraditórios, marcados por alianças entre classes, frações e camadas desses grupos em disputa de hegemonia em âmbito global. O líder sardo ajuda a corroborar a ideia de que a dominação de um país sobre outro também deve ser compreendida no campo da luta de classes, ainda que travada no interior do bloco histórico burguês. Partindo dessa perspectiva, a polêmica sobre a composição dos aspectos nacionais e internacionais na formação da classe dominante brasileira, para citar um exemplo que tem ocupado nossos debates, não tem sentido. Enxergo uma relação dialética entre elementos internos e externos que se imbricam contraditoriamente, não havendo a primazia de um sobre o outro. Ambos entrelaçam-se, não havendo lugar para a polêmica quanto à identificação do elemento sobre o qual está fundamentada a dependência brasileira: raízes coloniais ou inserção periférica? A burguesia brasileira é resultado de um processo no qual esses dois elementos se entrelaçam, uma vez que essa classe já surge no contexto do desenvolvimento global do capitalismo. Origina-se, portanto, já sob a condição de subalternidade. Assim, as burguesias nacionais são incapazes de liderar um projeto de caráter patriótico, uma vez que seu objetivo é fazer a disputa de hegemonia no interior desse bloco histórico global, não romper com ele.

Se as ideias dominantes são as ideias das classes dominantes, a constituição de uma ideia hegemônica só pode ser entendida como a constituição da própria hegemonia de classe. A grande contribuição de Gramsci está em permitir que visualizemos a complexidade desses processos, as interconexões, níveis e estágios que estruturam esses fenômenos. Em grande medida, destaca-se o elemento cultural da reflexão do intelectual italiano, ou o debate quanto às frações de classe, para compreender a composição de alianças e a luta de massas em disputa de hegemonia. Absolutamente compreensível, diante do economicismo e do esquematismo que orientaram boa parte das interpretações marxistas ao longo do século XX. Entretanto, limitar o pensamento do dirigente e intelectual marxista italiano ao âmbito da cultura, consiste em reducionismo que permite produzir visões distorcidas a respeito do seu pensamento e restringem a potencialidade de seu pensamento. Gramsci não apenas renovou o marxismo, mas permitiu novas e enriquecedoras interpretações e, por conseguinte, o desenvolvimento do pensamento de Marx.

Esta resenha poderia ser interminável se apresentasse aqui todos os temas e debates suscitados pela obra, tamanha é a sua contribuição e riqueza. Contudo, busquei destacar os elementos que se referem à compreensão do capitalismo como sistema global, em detrimento da visão hegemônica que caracteriza as relações internacionais apenas como relações interestatais pautadas pelo direito internacional. Assim, devemos resgatar Losurdo para compreender a relação entre a reprodução das concepções e dos valores ocidentais hegemônicos e a ruptura com eles. Dessa forma, é possível relembrar o caráter dialético entre as questões nacional e internacional no contexto das lutas de classes em toda a sua complexidade. Uma das grandes contribuições do livro, organizado por Ana Prestes e Diego Pautasso, consiste em 
compreender que as relações internacionais estabelecidas no âmbito de um sistema social de caráter global são pautadas pela força. Essas conexões são permeadas por contradições provocadas pelo estágio de desenvolvimento de cada país, o que determina a capacidade de cada nação em interferir nos rumos do planeta. Por isso, deve-se destacar a importância da URSS na constituição de uma nova forma de fazer relações internacionais, materializada na ajuda social e desinteressada a Cuba ou às lutas de independência na África. Da mesma forma, é fundamental destacar o papel da China. Ambas as experiências constituem potências de outra natureza, permitindo acumular força na construção de um novo sistema-mundo baseado em outros valores. Mas o objetivo ainda aponta para a ruptura com o atual sistema. Por fim, esse elemento permite fazer um gancho com outra questão importante, que nos leva à prática política de Marx. O revolucionário alemão foi artífice de um novo tipo de relações internacionais, com base nos princípios do internacionalismo proletário e na solidariedade com as lutas para a formação de um novo bloco histórico para disputar uma nova hegemonia global.

* Graduado em História pela Pontifícia Universidade Católica de São Paulo (PUC-SP) e mestre pelo Programa de Pós-Graduação em Integração da América Latina da Universidade de São Paulo (USP). Professor da rede privada de ensino do Rio Grande do Sul. Integra o grupo de trabalho do Espaço LatinoAmericano e Caribenho de Educação Superior para a III Conferência Mundial de Educação Superior da Organização das Nações Unidas para a Educação, a Ciência e a Cultura (Unesco). Compõe o movimento Kairós Educacional. Foi diretor de Relações Internacionais da Associação Nacional de Pós-Graduandos (ANPG), secretário-executivo da Organização Continental Latino-Americana e Caribenha de Estudantes, diretor de Solidariedade Internacional e Formação da União da Juventude Socialista (UJS) e vice-presidente da Federação Mundial das Juventudes Democráticas.

Texto recebido em 2 de novembro de 2021; aprovado em 3 de novembro de 2021.

\section{Referências bibliográficas complementares}

ARICÓ, José. Marx e a América Latina. Rio de Janeiro: Paz e Terra, 1982.

MARINI, Ruy Mauro. Dialéctica de la dependencia. Ciudad de México: Era, 1990.

PRESTES, Anita Leocadia. Luiz Carlos Prestes: um comunista brasileiro. São Paulo: Boitempo, 2015. QUIJANO, Aníbal. Colonialidad del poder, eurocentrismo y América Latina. In: LANDER, Edgardo (Org.). La colonialidad del saber: eurocentrismo y ciencias sociales - perspectivas latinoamericanas. Buenos Aires: Clacso, 2000. p. 203-241. 